\title{
VALIDATION METHODS FOR THE ANALYSIS OF HYDROXYPROLINE FROM COLLAGEN UNDENATURED TYPE II COLLAGEN USING HIGH-PERFORMANCE LIQUID CHROMATOGRAPHY FLUORESCENCE
}

\author{
BAITHA PALANGGATAN MAGGADANI, HARMITA*, MILZA LUBNAN
}

Department of Pharmacy, Faculty of Pharmacy, Universitas Indonesia, Depok 16424, Indonesia. Email: igakadeharmita@gmail.com Received: 17 June 2018, Revised and Accepted: 12 August 2018

\section{ABSTRACT}

Objective: This study aimed to validate an high-performance liquid chromatography method for analyzing undenatured Type II collagen preparations using a fluorescence detector.

Methods: Based on the optimum analysis conditions, the compound was detected at an excitation wavelength of $255 \mathrm{~nm}$ and an emission wavelength of $320 \mathrm{~nm}$. The optimum mobile phase was determined to be acetate (pH 4.2) and acetonitrile (60:40) with a flow rate of $1.0 \mathrm{ml} / \mathrm{min}$. Hydroxyproline is a compound that does not have chromophore moiety; thus, it has to be derivatized first using 9-fluorenylmetoxycarbonyl-chloride.

Results: The developed method was validated with linearity and an equation of $y=3,249,704 x+141,945,072$, with a value of $r=0.9994$. The detected range of hydroxyproline was $4-15 \mathrm{ppm}$. The limit of detection was determined to be 0.49 , with an limit of quantitation of 1.64 .

Conclusion: Our results indicated that the average level of hydroxyproline was 98.66\%, 99.12\%, and 99.85\%.

Keywords: Derivatization, Fluorescence, High-performance liquid chromatography, Hydroxyproline, Optimization, Validation.

(C) 2018 The Authors. Published by Innovare Academic Sciences Pvt Ltd. This is an open access article under the CC BY license (http://creativecommons. org/licenses/by/4. 0/) DOI: http://dx.doi.org/10.22159/ijap.2018.v10s1.89

\section{INTRODUCTION}

Collagen is currently in high demand for various industries, including those related to food, pharmacy, and cosmetics. However, the exact characteristics of collagen depend largely on the raw materials and extraction conditions used [1]. Two types of collagen exist, namely, denatured and undenatured collagen. Undenatured collagen is termed undenatured Type II collagen (UC-II) and is derived from chicken sternum cartilage. UC-II contains a number of amino acids, including hydroxyproline, which is a secondary amino acid derived from the proline in collagen and some plant proteins [2]. Some proteins undergo the post-translational modification of proline by the proline hydroxylase enzyme [3]. In recent years, collagen has been used to address several health problems, particularly those affecting the joints. Indeed, the prevalence of joint disorders in Indonesia is approximately $11.92 \%$. Osteoarthritis is the most common arthritis and can affect all joints in the body [4]. According to studies, UC-II can reduce the destruction of collagen in the body, inducing anti-inflammatory activity and improving joint flexibility [5]. UC-II can also significantly reduce levels of circulating cytokines and associated inflammation, serving to decrease the severity of arthritis [6].

The analysis of the hydroxyproline content of collagen has been previously reported using high-performance liquid chromatography (HPLC). Aditya analyzed the glycine, proline, and hydroxyproline content of type I collagen extracted from pigskin [7]. The authors used 9-fluorenilmetoksikarbonilchloride (FMOC-Cl) as a derivatization agent. Other reagents that can be used to derivatize amino acids are ortho-phthalaldehyde, 2-Mercaptoethanol or 1-dimethylaminonaphthalene-5-sulfonyl chloride (dansyl chloride) [8]. However, Aditya chose to use FMOC-Cl because hydroxyproline is a secondary amino acid with values of limit of detection (LOD) and limit of quantitation (LOQ) of 0.900 and 3.001, respectively [7].

In this study, we validated an HPLC analytical method for UC-II using FMOC-Cl as a derivatization agent, because hydroxyproline has a special role in the structure of collagen and its large components $(21 \%)$. The validation of an HPLC method for hydroxyproline using a fluorescence detector is needed to improve on previous studies.

\section{MATERIALS AND METHODS}

\section{Materials}

Three samples of UC-II (A, B, and C), L-hydroxyproline (Famouschem Co., Ltd.), FMOC-Cl (Hangzhou Dingyan Chem Co., Ltd.), aqua pro injection (Ikapharmindo Putramas), aquadest (Brataco), acetonitrile pro HPLC (Merck), $\mathrm{NaOH}$ (Merck), boric acid (Merck), glacial acetic acid (Merck), sodium acetate anhydrous (Merck), and HCl (Merck) were used in this study.

\section{Tools}

The HPLC (Shimadzu) system consisted of a pump, a Shimadzu ${ }^{\circledR}$ C18 column, a fluorescence detector, a manual injector, and a data processing module on a computer. Additional tools used in the quantitative analysis included KCKT syringes (SGE, Australia), a pH meter (Eutech $\mathrm{pH}$ 510), analytical scale (Acculab), centrifuge (NF 400R), vortex (WiseMix VM-10), micropipettes (Socorex), microtubes, and common beakers.

\section{Methods \\ Standard solutions}

A hydroxyproline stock solution was prepared by dissolving $100 \mathrm{mg}$ hydroxyproline into a volumetric flask and adding $100 \mathrm{ml} \mathrm{HCl} 0.1 \mathrm{M}$.

\section{Optimization of analysis conditions}

The optimization of analysis conditions was performed using three different variations of wavelength, mobile phase composition, and flow rate. The analysis was performed by preparing a $300 \mu \mathrm{l}$ aliquot of hydroxyproline standard solution, followed by the addition of $300 \mu \mathrm{l}$ of borate buffer ( $\mathrm{pH} 9.3$ ) and $300 \mu \mathrm{l}$ of FMOC-Cl (1.5 mM; in acetonitrile). Sample aliquots $(20 \mu \mathrm{l})$ were then injected into the HPLC. The samples were tested by ultraviolet-visible (UV-Vis) spectrophotometry to 
determine the excitation and emission wavelengths using the HPLC under normal analysis conditions at wavelengths of $320 \mathrm{~nm}, 325 \mathrm{~nm}$, and $330 \mathrm{~nm}$. The largest wavelength peak area was then used. For the optimization of the mobile phase, variations of the acetate buffer mobile phase $(\mathrm{pH} 4.2)$ were evaluated using ratios of $65: 35,55: 45$, and $60: 40$. The $20 \mu \mathrm{l}$ of samples were injected into the HPLC at a flow rate of $0.8 \mathrm{ml} / \mathrm{min}, 1.0 \mathrm{ml} / \mathrm{min}$, and $1.2 \mathrm{ml} / \mathrm{min}$. The optimal analysis conditions were rated based on the separation of two close or resolution (R) peaks, peak sharpness, the tailing factor $\left(T_{f}\right)$, the retention time $\left(t_{R}\right)$ of peak discharge, and column efficiency (the number of theoretical plates $[\mathrm{N}]$ ), and the height equivalent to a theoretical plate (HETP).

\section{Conformity assessment system}

A $300 \mu \mathrm{l}$ hydroxyproline standard solution was added to $300 \mu \mathrm{l}$ borate buffer (pH 9.3) and $300 \mu \mathrm{l} \mathrm{FMOC-Cl} 1.5 \mathrm{mM}$ (in acetonitrile). A $20 \mu \mathrm{l}$ sample was then injected into the HPLC system with the chosen flow rate and mobile phase composition. The conformity assessment system was conducted by injecting the samples 6 times. The peak sharpness, $t_{R}$, number of theoretical plates $(N)$, precision $(K V)$, HETP, and $T_{f}$ were then recorded.

\section{Validation of analytical method}

\section{Calibration curve and linearity test}

A calibration curve of the test solutions was made using hydroxyproline standard solutions at concentrations of $4,6,8,10$, and $15 \mu \mathrm{g} / \mathrm{ml}$. The derivatization was then performed based on sample preparation steps. Each $20 \mu \mathrm{l}$ standard solution was injected into HPLC. From the obtained data, the regression of the peak area (y) to analyte concentration ( $\mathrm{x}$ ) was analyzed, and the calibration curve was made. The correlation coefficient ( $r$ ) from the linear regression equation was then calculated to evaluate the linearity of the curve. From the regression line, the LOD and LOQ could be determined.

\section{Precision and accuracy test}

This experiment was performed using a simulation method. The concentrations were $80 \%, 100 \%$, and $120 \%$. A $100 \%$ concentration was assumed by $100 \mathrm{mg}$ hydroxyproline, while $80 \%$ and $120 \%$ were assumed to be $80 \mathrm{mg}$ and $120 \mathrm{mg}$ hydroxyproline, respectively. The preparation of samples was performed by pipetting $300 \mu \mathrm{l}$ of the solution and adding $300 \mu \mathrm{l}$ of borate buffer $(\mathrm{pH} 9.3)$ and $900 \mu \mathrm{l}$ FMOC-Cl $1.5 \mathrm{mM}$ (in acetonitrile). A $20 \mu \mathrm{l}$ sample was then injected into the HPLC system and the peak area was recorded. Three replicas

Table 1: Excitation and emission wavelength selection

\begin{tabular}{lll}
\hline Wavelength & & $\begin{array}{l}\text { Area of } \\
\text { Hydroxyproline }\end{array}$ \\
\cline { 1 - 2 } Excitation (nm) & Emission (nm) & \\
\hline \multirow{2}{*}{255} & 320 & 202.304 .692 \\
& 325 & 144.723 .212 \\
& 330 & 102.378 .246 \\
\hline
\end{tabular}

of each concentration were made, and the level, recovery percentage (percentage recovery), and percentage KV were calculated.

\section{Selectivity test}

Each $20 \mu$ l solution was injected into the HPLC system under the chosen conditions to observe whether there were any $t_{R}$ differences between the samples and the standard solution and whether there was another peak discharged at the same time as the hydroxyproline $t_{R}$ in the sample solution.

\section{Determination of sample levels}

The determination of sample levels was performed using three different samples. Each sample got the same treatment. The table weights of samples A, B, and C were 0.633 gr or $\pm 40 \mathrm{mg} \mathrm{UC}-\mathrm{II}, 0.4613 \mathrm{gr}$ or $\pm 40 \mathrm{mg}$ UC-II, and 0.4609 gr or $\pm 40 \mathrm{mg}$ UC-II, respectively. Each powder was dissolve in $100 \mathrm{ml} \mathrm{HCl} 0.1 \mathrm{~N}$. Afterward, a $300 \mu \mathrm{l}$ sample was obtained to be derivatized and was added to $300 \mu \mathrm{l}$ of borate buffer ( $\mathrm{pH} 9)$ and $900 \mu \mathrm{L}$ FMOC-Cl $1.5 \mathrm{mM}$ (in acetonitrile). Then, the $20 \mu \mathrm{l}$ sample was injected into the HPLC system under the selected conditions, and the peak areas were recorded. The experiment was repeated 3 times. The levels were then calculated using the calibration curve equation.

\section{RESULTS AND DISCUSSION}

The analysis for the optimum wavelength was important for analyzing compounds using the fluorescence detector of the HPLC, as it was important to improve the selectivity and sensitivity of the compound to be analyzed [9]. The analysis of hydroxyproline using a fluorescence detector HPLC method requires a derivatization step to increase sensitivity [10-13]. A fluorogenic reactor was used in the derivatization process to detect compounds with the fluorescence detector. In this experiment, three wavelength variations of 320,325 , and $330 \mathrm{~nm}$ were used (Table 1).

To measure the excitation wavelength, UV-Vis spectrophotometry was used and it obtained an excitation wavelength of $255 \mathrm{~nm}$. Results using a $255 \mathrm{~nm}$ excitation wavelength and a $320 \mathrm{~nm}$ emission wavelength resulted in the largest peak area, which was 202,304,692. The mobile phase composition at 60:40 was chosen compared to 55:45 and 65:35 because it gave a shorter $t_{R}$, higher resolution rate, a large number of theoretical plates, a small number of HETP, and a $\mathrm{T}_{\mathrm{f}}$ closer to 1 (symmetric) (Table 2). At a $0.8 \mathrm{ml} / \mathrm{min}$ flow rate, the hydroxyproline $t_{R}$ was $7.6 \mathrm{~min}$. At a flow rate of $1.0 \mathrm{ml} / \mathrm{min}$, the hydroxyproline $t_{R}$ was $6.2 \mathrm{~min}$, while at $1.2 \mathrm{ml} / \mathrm{min}$, the hydroxyproline $t_{R}$ was $5.2 \mathrm{~min}$. The fastest flow rate was $1.2 \mathrm{ml} / \mathrm{min}$; however, this resulted in a pump pressure that was too high, which can block the entrance to the column. Therefore, we chose a flow rate of $1.0 \mathrm{ml} / \mathrm{min}$ (Table 3).

The conformity assessment system was required before an analysis method was chosen because it was possible there were many variations of the tools and techniques used for analysis; thus, we needed to ensure the effectiveness and validity of the operational system and obtain

Table 2: Mobile phase composition selection

\begin{tabular}{|c|c|c|c|c|c|}
\hline Mobile phase composition & Retention time (min) & $T_{f}$ & HETP (mm/plat) & Number of theoretical plates $(\mathrm{N})$ & Resolution \\
\hline Buffer acetate: acetonitrile (60:40) & 5.677 & 1.794 & 0.1425 & 1754 & - \\
\hline Buffer acetate: acetonitrile (65:35) & 7.707 & 1.726 & 0.1501 & 1665 & - \\
\hline Buffer acetate: acetonitrile (55:45) & 4.300 & 1.733 & 0.1200 & 2082 & - \\
\hline
\end{tabular}

$\mathrm{T}_{\mathrm{f}}$ : Tailing factor, HETP: Height equivalent to a theoretical plate

Table 3: Flow rate selection

\begin{tabular}{|c|c|c|c|c|c|}
\hline Flow rate $(\mathrm{mL} / \mathrm{min})$ & Retention time (min) & Tailing factor $\left(T_{f}\right)$ & HETP (mm/plat) & Number of theoretical plates $(\mathrm{N})$ & Resolution \\
\hline 0.8 & 7.661 & 1.601 & 0.1406 & 1778 & - \\
\hline 1.0 & 6.200 & 1.663 & 0.1549 & 1613 & - \\
\hline 1.2 & 5.218 & 1.575 & 0.1200 & 2082 & - \\
\hline
\end{tabular}

HETP: Height equivalent to a theoretical plate, $\mathrm{T}_{\mathrm{f}}$ : Tailing factor 
valid results [10]. This test was conducted using a buffer acetate (pH 4.2):acetonitrile (60:40) mobile phase at a flow rate of $1.0 \mathrm{ml} / \mathrm{min}$. We repeated the test over six injections, resulting in a $1.640 \mathrm{~T}_{\mathrm{f}}$ value; 0.1317 of HETP; and 1897 number of theoretical plates; with $1.02 \%$ for the coefficient of variation. The data met the requirements of the conformity assessment test because the repeated value of the coefficient variation was $<2 \%(\leq 2 \%)$.

Based on our calculation of the linear regression statistics, the equation for the hydroxyproline calibration curve was $y=3,249,704$ $x+141,945,072$, where $x$ was the concentration of hydroxyproline and $\mathrm{y}$ was the peak area of hydroxyproline. The hydroxyproline calibration curve contained $4,6,8,10$, and $15 \mu \mathrm{g} / \mathrm{ml}$ hydroxyproline solutions derivatized by FMOC-Cl. The results of the hydroxyproline linearity test in the standard solution at 4-15 ppm revealed that the coefficient correlation ( $\mathrm{r}$ ) was 0.9994 . Thus, it can be concluded that the derivate compound forming between hydroxyproline and the FMOC-Cl solution met the linearity test $(\geq 0.9990)$ because the hydroxyproline had fairly

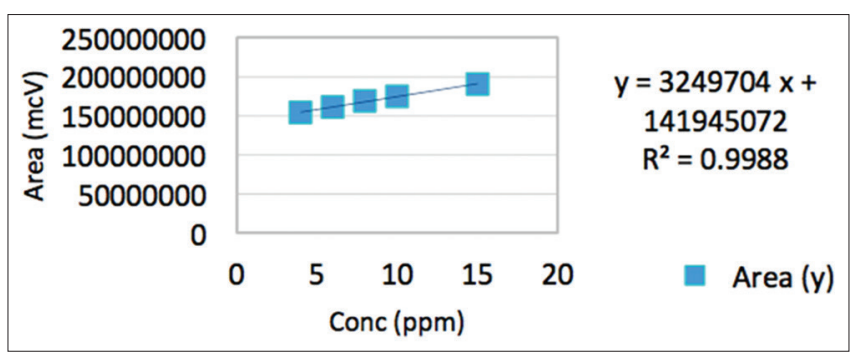

Fig. 1: Calibration curve good effectiveness. The limits of detection and quantitation were important to find out the lowest limit of the compound concentration, which can be determined using an accurate and precise method. The lower limits of the detection and quantitation showed that the method used to determine it was more sensitive [9]. The limits of detection and quantitation for hydroxyproline were obtained at 0.49 and 1.64, respectively. It can be concluded that the LOD and LOQ entered the concentration range used in the calibration curve test (Fig. 1).

The results of injecting $20.0 \mu \mathrm{l}$ placebo (matrix tablet) solution that was given the same sample and derivatized at the chosen conditions demonstrated that there was no interference at the $t_{R}$ of the hydroxyproline compound. The analytical method we used selectively detected the hydroxyproline derivative compound. The accuracy and recovery test was conducted by calculating the value of the recovery test (\%R). Our results showed that the values of the recovery test of the three replicas were different $(80 \%, 100 \%$, and $120 \%)$ for the tablet samples with each replica of the concentration meeting the $98-102 \%$ criteria. The precision or repeatability test was conducted by calculating the value of the coefficient of variation $(\% \mathrm{CV}$ ) from the three replicas for each concentration. In Harmita, the allowed coefficient of variation was $\leq 2 \%$. Thus, our data (Table 4) met the accuracy and precision criteria [9].

The determination of sample levels was performed using different samples. The results were calculated using the one-point measurement method. The average levels of hydroxyproline in samples A, B, and C were $98.66 \%$, 99.12\%, and $99.85 \%$ (Tables 5-7).

\section{CONCLUSION}

Based on our results, the optimum conditions for analyzing hydroxyproline levels in UC-II preparations with HPLC with a

Table 4: Accuracy and precision

\begin{tabular}{lllll}
\hline Concentration (ppm) & Peak area sample & Concentration measurable (ppm) & KV/SD (\%) & UPK (\%) \\
\hline \multirow{2}{*}{8} & $167,522,706$ & 7.87 & $0.035 / 0.44$ & 99.15 \\
& $167,595,612$ & 7.89 & & 100.01 \\
& $167,678,454$ & 7.92 & $0.048 / 0.49$ & 99.75 \\
10 & $174,142,115$ & 9.90 & 98.07 & 99.62 \\
& $174,005,349$ & 9.86 & $9.036 / 0.30$ & 99.53 \\
12 & $174,321,787$ & 9.96 & & 100.16 \\
\hline
\end{tabular}

SD: Standard deviation

Table 5: Determination of sample A

\begin{tabular}{lllll}
\hline Concentration (ppm) & Standard peak area & Sample peak area & Concentration hydroxyproline (mg/g) & Level (\%) \\
\hline \multirow{2}{*}{10} & \multirow{2}{*}{$171,365,791$} & $207,634,382$ & 2.02 & 98.43 \\
& & $207,948,812$ & 2.03 & 98.90 \\
\hline
\end{tabular}

Table 6: Determination of sample B

\begin{tabular}{lllll}
\hline Concentration (ppm) & Standard peak area & Sample peak area & Concentration hydroxyproline (mg/g) & Level (\%) \\
\hline \multirow{2}{*}{10} & \multirow{2}{*}{$174,425,408$} & $204,851,297$ & 2.77 & 98.13 \\
& & $206,118,057$ & 2.82 & 100.10 \\
\hline
\end{tabular}

Table 7: Determination of sample C

\begin{tabular}{lllll}
\hline Concentration (ppm) & Standard peak area & Sample peak area & Concentration hydroxyproline (mg/g) & Level (\%) \\
\hline \multirow{2}{*}{10} & $171,365,791$ & $178,356,759$ & 2.80 & 99.31 \\
& & $178,750,544$ & 2.83 & 100.39 \\
\hline
\end{tabular}


fluorescence detector were at $\lambda_{\mathrm{ex}}=255 \mathrm{~nm}$ and $\lambda_{\mathrm{em}}=320 \mathrm{~nm}$. The Shimadzu ${ }^{\circledR} C_{18}$ column (column length of $250 \mathrm{~nm}$, inner diameter of $4.6 \mathrm{~nm}$, and particle size of $5 \mu \mathrm{m}$ ) with an acetate buffer solution mobile phase (pH 4.2):acetonitrile $(60: 40)$ and $1.0 \mathrm{ml} / \mathrm{min}$ flow rate were considered optimal. The optimum conditions for hydroxyproline were that it should be derivatized with $300 \mu \mathrm{l}$ of the FMOC-Cl reactor, with an injection volume of $20.0 \mu \mathrm{l}$. In the concentration range of $4-15 \mathrm{ng} / \mathrm{ml}$, the calibration curve for hydroxyproline was $\mathrm{y}=3,249,704$ $\mathrm{x}+141,945,072$ with a coefficient correlation (r) 0.9994 . The value of LOD was $0.49 \mathrm{ng} / \mathrm{ml}$, while that of LOQ was $1.64 \mathrm{ng} / \mathrm{ml}$. The average levels of hydroxyproline in samples A, B, and C were $98.66 \%, 99.12 \%$, and $99.85 \%$. The three samples met determination level requirements. For further research, it is necessary to validate the method of analysis of other amino acids contained in undenatured collagen II, as well as the development a method of determination of the main content amino acid levels in undenatured collagen II using other penderivates.

\section{CONFLICTS OF INTEREST}

Declared none.

\section{REFERENCES}

1. Schmidt MM, Dornelles RC, Mello RO, Kubota EH, Mazutti MA, Kempka AP, et al. Collagen extraction process. Int Food Res J 2016;23:913-22.

2. Engelking LR. Textbook of Veterinary Physiological Chemistry. Vol. 3. St. Louis, MO: Elsevier; 2015. p. 397-405.

3. Marshall WJ, Bangert SK. Clinical Biochemistry: Metabolic and Clinical Aspects. Churchill Livingstone/Elsevier. Available from: https://www.books.google.co.id/books?id=Je_pJfb2r0cC.
4. Health Research and Development Agency of the Ministry of Health of the Republic of Indonesia. Basic Health Research (Riskesdas). Jakarta: Indonesian Ministry of Health; 2013.

5. Crowley DC, Lau FC, Sharma P, Evans M, Guthrie N, Bagchi M, et al. Safety and efficacy of undenatured Type II collagen in the treatment of osteoarthritis of the knee: A clinical trial. Int J Med Sci 2009;6:312-21.

6. Lugo JP, Saiyed ZM, Lau FC, Molina JP, Pakdaman MN, Shamie AN, et al. Undenatured Type II collagen (UC-II $®$ ) for joint support: A randomized, double-blind, placebo-controlled study in healthy volunteers. J Int Soc Sports Nutr 2013;10:48

7. Aditya A. Isolation, Purification, and Collagen Characterization from Pig Skin, and Glisin, Prolin, and Hydroxyproline Analysis in Characterization of High Performance Liquid ChromatographyFluorescence. Depok: Thesis. Faculty of Pharmacy, Universitas Indonesia; 2017.

8. Rediatning W, Kartini N Analisis asam amino dengan kromatografi cairan kinerja tinggi secara derivatisasi prakolom dan pascakolom. Proceedings Institut Teknologi Bandung 1987; 20:41-59.

9. Harmita I. Phytochemicals Analysis. Depok: Faculty of Pharmacy, Universitas Indonesia; 2012

10. Kupiec T. Quality-control analytical methods: High-performance liquid chromatography. Int J Pharm Compd 2004;8:223-7.

11. Chakravarthy VA, Sailaja BB, Praveen KA. Stability indicating reverse phase high-performance liquid chromatographic method for simultaneous estimation of labetalol and its degradation products in tablet dosage forms. Asian J Pharm Clin Res 2016;9:242-9.

12. Siddiraju S, Kavitha R, Sudhakar M. Reverse phase high performance liquid chromatography method development and validation for the simultaneous estimation of gatifloxacin and flurbiprofen in pharmaceutical dosage form. Asian J Pharm Clin Res 2015;8:242-6.

13. Senthilraja M, Giriraj P. Reverse phase HPLC method for the simultaneous estimation of terbutanile sulphate, bromhexine HCL and guaifenesin in cough syrup. Asian J Pharm Clin Res 2011;4:13-5. 